\title{
BELAJAR PENDIDIKAN KARAKTER DARI SUNDA ( STUDI PADA KEPEMIMPINAN OTISTA)
}

\author{
Dedi Epriadi $^{1}$
}

\begin{abstract}
This research aims to lead by example leadership of Oto Iskandar DiNata sunda, in the midst of a crisis of character giving the leadership at this time. Using historical and qualitative approach method. The results of research that the establishment of theleadership character is influenced by the background of social, cultural, political, and linguistic typology leadership in Sundanese perspective ranging from To, Hookeun, Mukpruk, Ngulas so dapatdisarikan in leadership today's modern so that it can be utilized by current younger generation about lead by example from an Oto Iskandar DiNata.

Key Words: Kepemimimpinan, Sundanese, Oto Iskandar DiNata
\end{abstract}

\section{PENDAHULUAN}

Kepemimpinan dalam suatu organisasi merupakan hal yang sangat penting, bahkan memiliki peranan dalam menetukan keberhasilan atau kegagalan suatu organisasi bahkan dalam lingkup lebih luas dapat menentukan jatuh bangunnya suatu bangsa dan negara. Krisis yang melanda bangsa Indonesia pada saat ini silih berganti, menjadi bagian tak terpisahkan dalam perjalanan hidup bangsa ini. Krisis ekonomi, politik, sosial, budaya,moral, kepercayaan hingga krisis Agama. Namun krisis yang paling nyata dihadapi bangsa Indonesia adalah krisis Kepemimpinan. Kita mengalami keraguan menentukan figur-figur pemimpin teladan yang dapat menjadi panutan, yang mampu mengeluarkan bangsa Indonesia dari berbagai krisis multidimensi ini.

Memahami karakteristik kepempimpinan seseorang harus dilihat dari dua hal yaitu, karena faktor sosial, budaya, dan politik yang membentuknya dan yang kedua karena faktor lingkungan sosial yang dihadapinya sehingga mengharuskan dia melakukan itu.Meninggalnnya Oto Iskandar DiNata (dengan penuh kemisterian dan kontroversi), masyarakat sunda kehilangan tokoh penggerak yang berani sebagai putra Sunda yang mempunyai karya nyata dalam memperbaiki kondisi sosial, ekonomi, dan kemasyarakatan Sunda, yang juga memiliki andil besar dalam mempersiapkan kemerdekaan Indonesia.

\section{METODE PENELITIAN}

Penelitian ini menggunakan metode kualitatif dengan pendekatan sejarah. Cresswel (2010: 21-22) menjelaskan bahwa penelitian kualitatif merupakan metode yang mengeksplorasi dan memahami makna yang oleh sejumlah individu atau kelompok orang dianggap berasal dari masalah social. Dalam memperoleh data yang dibutuhkan sebagai bahan pembuatan penelitian, ada beberapa teknik, cara atau metode yang dilakukan oleh peneliti dan disesuaikan dengan jenis penelitian kualitatifyaitu : Pengamatan (observation), Wawancara, Dokumentasi, Studi Kepustakaan, Triangulasi, Forum Group Diskusi.

\footnotetext{
${ }^{1}$ STIA Setih Setio Muara Bungo
} 
Analisis data menggunakan Hubersman dalam Sugiono (2007: 91) bahwa aktivitas data dalam kualitatif filakukan secara interaktif dan berlangsung secara terus menerus sampai tuntas sehingga datanya sudah jenuh. Aktivitas dalam analisis data, yatu data reduction, data display, dan conclusion drawing/verification.

\section{PEMBAHASAN}

Memahami karakteristik kepemimpinan seseorang harus dipahami sebagai suatu yang didapatkan melalui proses dialog yang terus-menerus dengan berbagai pengalaman kehidupannya. Seseorang yang mempunyai gaya kepemimpinan tertentu, dapat dipahami dari dua hal, yaitu pertama, karena faktor lingkungan sosial, budaya, dan politik yang membentuknya sehingga memiliki karakteristik yang seperti itu (faktor bawaan) dan kedua, karena faktor lingkungan sosial yang dihadapinya yang mengharuskan dia melakukan hal itu. Dengan demikian, memahami latar belakang kehidupannya serta memahami keadaan lingkungan yang dihadapinya merupakan dua hal yang diperlukan dalam memahami karakteristik serta gaya kepemimpinan seseorang.

\section{Latar Belakang Pembentukan Karakter Kepemimpinan}

Lingkungan keluarga merupakan lingkungan yang pertama dan utama dalam kehidupan manusia.Lubis, (2003: 15) mengemukakan bahwa Bojongsoang merupakan lingkungan yang merupakan areal persawahan yang subur. Sawah yang demikian luas kala itu di Bojongsoang dapat dikaitkan dengan banyaknya padi yang bergudang-gudang yang dimiliki oleh keluarga Oto Iskandar di Nata, sebagaimana yang dituturkan oleh keturunan panyawah Ayahanda Oto. Lingkungan persawahan membentuk karakter seorang yang ramah, sedangkan pada sisi lain kehidupan jaman kolonial yang membentuknya menjadi seorang yang suka berterus terang dan pemberani.

\section{Latar Belakang Sosial}

R. Oto Iskandar di Nata dilahirkan pada tanggal 31 Maret 1897 di Bojongsoang, Kabupaten Bandung dari pasangan Raden Haji Rachmat Adam, Kepala Desa Bojongsoang dan Nyi Raden Siti Hatijah. Oto Iskandar di Nata adalah anak ketiga dari delapan bersaudara, yaitu Raden Ating Atma di Nata, Raden Pandi Prawira di Nata, Raden Oto Iskandar di Nata, Raden Endang Wiria di Nata, Raden Onong Soma di Nata, Nyi Raden Soekaesih, Nyi Raden Soekaemi, dan Nyi Raden Ratnaningsih. Keluarga R. Oto Iskandar di Nata adalah keluarga bangsawan atau menak Sunda. Hal tersebut dapat ditelusuri sampai tujuh generasi ke atas berasal dari keluarga Bupati Bandung.

Lubis,( 2003 : 9-10) menyebutkan dari salah satu sumber yang menyatakan bahwa ayah R. Oto Iskandar di Nata adalah Raden Natadimadja alias Raden Rahmat Adam, Lurah Bojongsoang. Kakeknya adalah Raden Nataredja yang juga pernah menjadi Lurah Bojongsoang. Buyut-nya adalah Raden Wangsapradja adalah Lurah Cigebar, Bojongsoang. Bao-nya adalah Raden Wirakoesoemah alias Raden Raksapradja adalah Kepala Pesawahan di Margasari Buahbatu. Janggawareng-nya adalah Raden Bradjadinata. Udeg-udeg-nya adalah Raden Adikoesoemah, Bupati Timbanganten. Dan Gantungsiwur-nya adalah Raden Anggayuda adalah Bupati Batulayang 
Lubis, (2003:14), mengemukakan bahwa sebagai seorang anak kepala desa, R. Oto Iskandar di Nata memiliki peluang yang sangat terbuka untuk bersekolah bila dibandingkan dengan anak-anak dari rakyat biasa. Oleh karena itu, ia dimasukkan ke HIS (Hollandsch Inlandsche School), sekolah dasar pribumi Belanda. Sekolah tersebut merupakan sekolah yang mengutamakan status orangtua, baik dilihat dari segi keturunan, jabatan, pendidikan maupun kekayaan. Hal ini menunjukan bahwa Oto memiliki latar belakang sosial yang berasal dari keturunan menak. Hasil wawancara dengan Guru Besar Sejarah Unpad Sobana Harjasaputra, yang mengemukakan bahwa :

menyangkut latar belakang dari kehidupan yang melandasinya......dan harus dihubungkan dengan latar belakang keluarganya dan bagaimana kehidupan menak sunda pada umumnya waktu itu. Mana yang terkesan sesuai dengan jiwa Oto, pemikiran Oto dan mana yang menyebabkan kemudian jiwa Oto bangkit. Karena pada waktu itu zaman Hindia- Belanda. Sampai sekarang masih ada orang yang mengatakan bahwa Bupati pada zaman penjajahan Belanda itu antek antek Kolonial, pemeras rakyat. eeeeh nanti dulu kata saya Nah Masalah itu harus dianalisis karena pada waktu itu ...menyangkut status sosial...dan status sosial umumnya urang Sunda pada umumnya kan pada zaman penjajajhan .ada golongan menak, golongan Santana, dan golongan cacah. Oto sepertinya paling tidak Oto masuk pada golongan Santana. Kan golongan menak mah sok disebut menak pangluhurna. Karena leluhurna kalebet menak teras seperti luluhurna Bupati.

Berdasarkan pendapat Lubis, dan hasil wawancara di atas dapat dimaknai , bahwa Oto berasal dari keturunan menak, Harjasaputra menyatakan Oto berasal dari golongan menak Santana, yang pada zaman Hindia Belanda memiliki peluang untuk mendapatkan pendidikan lebih tinggi dari masyarakat pribumi pada umumnya, akan tetapi meskipun berasal dari keluarga menak Oto sejak kecil telah memiliki jiwa kerakyatan, juga merupakan anak yang giat, jujur dan suka berterus terang, sehingga banyak yang menyukai dan mengaguminya

\section{Latar Belakang Budaya}

R.Oto Iskandar di Nata mendapatkan gemblengan pendidikan nilai budaya dari dua budaya yaitu agama Islam dan budaya Belanda karena pada masa itu golongan menak bisa mendapatkan pendidikan di sekolah Belanda, seperti yang dikemukakan oleh Lubis, ( 2003: 15), bahwa Oto mendapat pendidikan barat disatu sisi dan mendapat pendidikan pesantren di sisi lain. Bagi keluarga menak biasanya mendapat dua pendidikan, yakni sekolah Barat dan pendidikan agama. Penekanan agama di keluarga Oto nampaknya sangat intensif, mengingat ayahandanya adalah seorang kepala desa yang telah menunaikan ibadah haji. Dan haji pada waktu itu dianggap lebih terpandang daripada masyarakat awam.

Tipologi kepemimpinan modern di korelasikan dengan Dasa Pasanta Kepemimpinan Sunda (Hidayat suryalagi, PR, 29 Juli 2000)

a. Guna, berarti pemimpin memberikan pengertian kegunaan perintah seorang pemimpin kepada bawahan agar terjadi kesamaan persepsi hal ini relatif sama dengan indikator kepemimpinan modern Satu visi.

Hal tersebut identik dengan pernyataan ( Yahya, 2008:135) 
“ pasundan itu suatu perkumpulan nasional yang menuju persatuan Indonesia. Kalau dilihat dari lingkungan kebangsaan, pasundan itu satu pergerakan kebangsaan yang tidak melulu bersifat politik saja tetapi juga satu pergerakan yang mementingkan perihal pengajaran, kebudayaan ( seni), social, ekonomi , pendek kata semua syarat yang perlu untuk masyarakat kita. Bagi yang melihat pasundan sambil lalu saja, banyak yang berpendapat bahwa pasundan itu hanya perkumpulan social saja. Memang, ahli politik menghendaki pasundan menjdi sepenuhnya menjadi perkumpulan politik. Ahli social meminta supaya pasundan segenapnya menajdi badan social. Sebetulnya pasundan suatu perkumpulan yang menghendaki politik, social dan ekonomi. Memang Pasundan tentang perguruannya lebih pesat dari pada ke ekonomian dan kepolitikannya. Biarpun serba dikit, dengan dikutkan dengan bukti-bukti, pasundan telah turut berbakti untuk kemajuan dan kemuliaan bangsa, tanah air dan masyarakat".

(yahya, 2008:136)

“ persatuan itu bisa terdapat dengan jalan jalan unitaris dan federalis. Unitaris yaitu satu jalan untuk mencapai persatuan, dengan tidak mementingkan keadaan dan maing-masing golongan. Sedang federalis juga jalan persatuan, hanya dengan mementingkan pusaka-pusaka golongan, seperti bahasa. Jadi disini ternyata, bahwa dakwaan pada pasundan provinsialistis, yang berarti mengasingkan diri dari golongan-golongan Indonesia yang lain, salah sekali. Pasundan menjunjung. Sebetulnya memang membutuhi persatuan, hanya dengan jalan federasi. Begitulah citacita pasundan tentang pembangunan persatuan Indonesia itu. Tapi hendaklah di ingat, bahwa mendalamnya perasaan ke - indonesiaan itu tidak akan tercapai dengan jalan maki-makian, melainkan dengan jalan kepercayaan dan harga-menghargai.

b. Ramah yang mempunyai pengertian bahwa perintah yang disampaikan dengan ramah tamah dan halus budi sehingga yang diperintah merasa dihargai sebagai manusia hal ini identik dengan indicator kepemimpinan modern yakni keyakinan kuat mengenai Visi yang akan di capai.

" BU dan pasundan sebenarnya sejalan. Pasundan sudah ada dan sedikit tenang, tetapi aneh mengapa ngotot saja sunda harus mengikuti jawa, buka jawa yang sedikit yang mengikuti sunda?.... apakah demokratis itu yang banyak mengikuti yang sedikit.

c. Hookeun yang berarti kepercayaan diri orang yang diperintah dapat ditumbuhkan dengan cara menghargai prestasi kerjanya, hal ini sejalan dengan indicator percaya diri, dimana seorang pemimpin harus membangun rasa percaya diri kepada para bawahannya dengan cara memotivasi agar visi yang dibangun dapat tercapai.

Yahya (2008:139)

"Pemuda harus sanggup menjadi harapan bangsa, harus menyusun generasi baru yang sanggup generasi baru yang sanggup menerima pekerjaan yang akan ditimpahkan diatas bahunya, pemuda harus berani memperbaiki susunan masyarakat yang telah bobrok, dengan semangat baru yang selaras dengan keadaan. Pemuda harus berani menyusun kebudayaan yang baru, 
kebudayaan dunia segenapnya. Pemuda harus berani menyusun kebudayaan yang baru, kebudayaan dunia segenapnya. Pemuda harus berani meneruskan generasinya, harus berani meneruskan sejarah bangsanya untuk kemuliaan kemanusiaan seumumnya"

d. Pesok yang mempunyai pengertian pemimpin perlu sering melakukan silahturami untuk mengikat hati orang-orang yang dipimpinnya serta menimbulkan perasaan tenang. Hal ini sejalan dengan hubungan kepemimpinan karismatik dengan respek; identitas kolektif dan terhadap kinerja kelompok serta berhubungan langsung dengan kepercayaan, kepuasan dan pemberdayaan.

e. Asih mempunyai pengertian bahwa orang diperintah ikut memiliki rasa tanggung jawab, dimana pemimpin harus menunjukkan rasa sayang sehingga menimbulkan keteladanan.

f. Mukpruk mempunyai pengertian bahwa kepemimpinan perlu memberi kepercayaan kepada bawahan, sehingga mereka merasa dihargai kemampuannya. yahya (2008:73)

"sekalipun sudah menjadi kewajiban dalam organisasi setiap badan ( bagian) paguyuban pasundan harus tunduk dan taat terhadap tugas paguyubannya, disini kami tidak akan bosan menyampaikan banyak terima kasih untuk komite kongres Paguyuban cabang Cianjur yang sudah memperlihatkan kesetiaan dan ketaatan kepada paguyuban pasundan secara umum, dalam mempersiapkan kelengkapan untuk kongres yang baru lalu, semuanya sangat memuaskan. Semuanya, umpamanya saja: tempat kongres, penginapan para utusan, pelayanan selama pertemuan, pentas seni dan banyak dan banyak lainnya lagi. Hal ini tak ada lain selain kesigapan tuan rumah, pasundan Cianjur dan komite kongresnya ataupun sebaliknya. Malahan ada yang lebih dari semua itu, malam senin kemarin kongres usai , hari ini sudah salut, mudah-mudahan jadi contoh bagi cabang-cabang pasundan yang lainnya"

g. Ngulas mempunyai pengertian bahwa kepemimpinan dituntut menumbuhkan kesadaran kepada bawahan agar tidak melaksanakan pekerjaan karena terpaksa dan dalam hal ini adalah kemampuan pemimpin menggungkapkan Visi dengan agar bawahan dalam melaksanakan pekerjaan tidak dengan terpaksa dan ini menimbulkan rasa memiliki yang kuat para bawahan terhadap institusi dimana mereka mengabdikan diri.

Yahya (2008:140)

“ Pemuda sunda! Pasundan adalah tanah air kalian! Kalian yang punya kewajiban mengabdi demi tanah air, tetapi disamping kewajiban itu, kalian memiliki hak untuk hidup ditanah sendiri. Ini adalah menurut patokan: kewajiban dan hak. Pemuda sunda! Kalau kalian tidak bersungguh-sungguh mengasah diri, bukan mustahil, pemuda sunda di tanah airnya tidak mendapat bagian, terpaksa harus berkosong tangan, sebab kalah oleh golongan lain. Oleh sebab itu para pemuda sunda cepat buka mata, cepat kumpulkan tenaga dan senjata, yang dibangun dengan pengetahuan dan tabiat yang kuat, yaitu: kesungguhan, kemauan, ketekunan, niat yang kuat dan keberanian. Kalau tidak demikian, akan sia-sia, pasti pemuda sunda terdesak di medan perang dalam mencari penghidupan. Coba bayangkan, 
bagaimana prihatinnya kalau pemuda sunda hanya mendapat harkat kuli dan jongos, paling tinggi jadi jadi juru tulis, ringkasnya hanya menjadi pelayan, dan itu ditanah air sendiri. Aduh tobat, kalau harus sampai demikian. Tidak, jangan sampai begitu, jauhkan yang seperti itu dari tanah sunda."

h. Nyecap mempunyai pengertian bahwa pemimpin dalam mengkritik pekerjaan bawahan harus dilakukan dengan cara arif, teliti dan bijaksana dalam hal ini seorang pemimpin mempunyai rasa kepekaan akan lingkungan sekitar terutama terhadap bawahan.

"Pada sore hari kami berkunjung ke rumah Eyang di Bojongsoang. Saya masih ingat, kalau mobil kami sudah mendekati rumah Eyang, penduduk setempat segera berjongkok di pinggir jalan, tangan mereka dengan posisi "munjungan" ke arah kami. Masyarakat setempat sangat menaruh hormat kepada Bapak dan keluarganya, tetapi Bapak tidak senang diperlakukan secara berlebihan begitu dan selalu menegur mereka supaya menghentikan kebiasaan itu"

Pengalaman Martini tentang sikap Oto di atas menunjukan bahwa Oto seorang yang berpikiran modern, dan mencerminkan pemikiran Oto bahwa kedudukan atau derajat setiap manusia adalah sama sehingga Oto tidak mau diperlakukan dengan berlebihan. Seperti halnya Oto melarang istrinya untuk tidak berjalan gengsor ketika menghadap bupati .

Sedangkan hasil wawancara tertulis dengan lip D. Yahya (29 nopember 2016), mengemukakan bahwa :

Pa Oto lahir dari keluarga Sunda, dari penamaan dirinya (Oto ), atau (Ating, kakaknya), memperlihatkan budaya orang Sunda dalam memberi nama depan anak-anaknya. Oto lahir dan tumbuh berkembang dalam tradisi Sunda yang pada masa itu tengah menguat. Sebagaimana anak-anak Sunda pada awal abad XX, Oto mempelajari Islam secara tradisonal kepada ajengan dikampungnya (Bojongsoang), apalagi orangtuanya juga haji dan hajah yang pada saat itu masih jarang disandang oleh masyarakat. Sementara untuk pendidikan formal sebagai anak lurah, Oto medapatkan kemudahan untuk mengikuti sekolah HIS, HIK, hingga HKS. Dari latar belakang budaya itu dan pendidikan seperti itulah Oto tumbuh menjadi seorang nasionalis yang berakar pada budaya Sunda.

Berdasarkan kutipan hasil wawancara, sebagaimana anak-anak Sunda pada awal abad XX, Oto mempelajari Islam secara tradisonal kepada ajengan dikampungnya (Bojongsoang), apalagi orangtuanya juga haji dan hajah yang pada saat itu masih jarang disandang oleh masyarakat. Sementara untuk pendidikan formal sebagai anak lurah, Oto medapatkan kemudahan untuk mengikuti sekolah HIS, HIK, hingga HKS. Dari latar belakang budaya itu dan pendidikan seperti itulah Oto tumbuh menjadi seorang nasionalis yang berakar pada budaya Sunda. Dan berdasarkan uraian dari beberapa sumber di atas dapat dimaknai bahwa karakter kepemimpinan Oto terbentuk oleh berbagai faktor budaya, seperti budaya barat yang menjadikannya orang yang suka berterus terang, disiplin, berani, berpikiran modern, kehidupan di asrama karakter guru, antara lain disiplin dan sabar, dibentuk setiap saat, selain itu tinggal di asrama menuntut Oto Iskandar di Nata untuk hidup mandiri. Sedangkan ajaran Islam 
menjadikannya seorang yang jujur, dan amanah. Budaya Sunda mengajarkannya untuk mencintai kesundaannya, menjadi seorang nasionalis yang berakar pada budaya Sunda dan Faktor - faktor budaya tersebut menjadi salah satu pembentuk karakter kepemimpinannya.

\section{Latar Belakang Politik}

Latar belakang pemikiran politik yang membentuk karakter kepemimpinan Oto terbentuk oleh berbagai faktor, seperti yang dikemukakan oleh Lubis, (2003: 17), bahwa R. Oto Iskandar di Nata mulai tertarik masalah politik dan kebangsaan semenjak sekolah di Hogere Kweekschool (Purwerejo) setelah banyak membaca koran De Express (Douwes Dekker). Setelah menamatkan sekolah di SGB, Oto Iskandar di Nata mendapat kesempatan melanjutkan sekolah ke Hogere Kweekschool (HKS) atau Sekolah Guru Atas di Purworejo, Jawa Tengah. Demikianlah proses yang dialami Oto, masuk asrama di SGB Bandung ternyata merupakan latihan yang sangat berguna untuk tinggal lebih jauh lagi dari keluarga. Sejak bersekolah di SGA Purworejo, proses pematangan Oto Iskandar di Nata mulai terlihat di sekolah tersebut. Ekadjati,( 2006 : 128), mengemukakan bahwa Oto sangat gemar membaca bacaan politik. Surat kabar yang biasa dibacanya pada waktu itu adalah De Express asuhan Douwes Dekker.Oto tertarik dengan pemikiran Douwes Dekker.

Douwes Dekker adalah pendiri Indische Partij, partai politik pertama di Hindia Belanda yang banyak mengkritisi kebijakan pemerintah Kolonial Belanda. Selain itu, tulisan-tulisan pada surat kabar itu terkenal sering mengecam Pemerintah Hindia Belanda, sehingga siswa-siswa HKS dilarang membacanya. Jiwa Oto terbentuk lebih matang melalui bacaan-bacaan tersebut Oto mulai tertarik pada masalah kemasyarakatan, kebangsaan, dan perjuangan bangsa. Inilah sebenarnya yang dikhawatirkan baik oleh guru-guru maupun pemerintah kolonial Belanda.

\section{SIMPULAN}

1. Latar belakang yang mempengaruhi kepemimpinan Oto

a. Latar belakang Sosial

Oto berasal dari keluarga bangsawan atau menak, namun dia tidak pernah merasa berbeda yang lain, Oto merupakan anak yang giat, jujur dan sukaberterus terang dan teman sebaya yang sering mengangkat Oto sebagai pemimpin dan dengan latar belakang sosial ini yang sangat besar mempengaruhi Oto untuk menjadi seorang pemimpian.

b. Latar belakang budaya

Oto mendapatkan gemblengan pendidikan nilai budaya dari dua budaya yaitu agama islam dan belanda karena masa itu golongan menak bisa mendapatkan pendidikan di sekolah belanda dimana Oto dimasa bersekolah tinggal di asrama dan sangat aktif and sering melanggar aturan asrama sehingga sering dihukum, namun tetap diimbangi kecerdasan. Dan sebagai pemberani Oto dalam mencetuskan gagasannya beliau memulai dari kalangan keluarganya sendiri dulu. Dan dari latar belakang budaya ini karakter kepemimpinan Oto terbentuk dan berbagai factor budaya seperti budaya barat yang menjadikannya orang yang suka berterus terang, disiplin, berani, berpikiran modern. Kehidupan 
di asrama dan karakter guru antara lain disiplin dan sabar dibentuk setiap saat. Selain itu tinggal di asrama membentuk Oto hidup lebih mandiri, sedangkan ajaran islam menjadikannya seorang yang jujur dan amanah. Budaya sunda mengajarkannya untuk mencintai kesundaannya, menjadi seorang Nasionalis yang berakar pada budaya sunda dan factor-faktor budaya tersebut menjadi salah satu pembentuk karakter kepemimpinannya.

c. Latar Belakang Politik

Oto mulai tertarik politik semenjak sering membaca bacaan yang berbau politik dan ini mempengaruhi jiwa politiknya dan ini di pengaruhi oleh pemikiran Dowes Dekker dan Oto sehingga secara kejiwaan politik Oto lebih matang dan menjadi guru dan pengurus Budi Otomo sebagai salah satu bentuk keterlibatan Oto dalam organisasi dan Politik karena Oto mempunyai kapasitas untuk mengurus Budi Utomo Pusat dan ini menimbulkan rasa nasionalisme Oto dan berkat kepemimpinan beliau Budi Utomo semakin maju dan berkembangdan begitu pula halnya dengan Paguyuban Pasundan dengan kehadiran beliau menjadikan Paguyuban Pasundan menjadi lebih berwarna dan lebih maju serta moderat.

2. Kebijakan Oto yang bersifat Visioner

a. Pemimpin adalah pelayan bagi masyarakat dan kebijakan sudah termasuk dalam kerangka NPS dan dalam kebijakan yang Oto hasilkan bahwa pemimpin itu adalah sebetulnya pelayan bagi yang di pimpin dan kebijakan ini sangat visioner dan ini berlaku sampai saat ini.

b. Membentuk BPP ( Bale Pemoelangan Pasoendan) dan kebijakan ini masih sangat relevan dimana setiap organisasi mempunyai cabang-cabang disetiap daerah dan hal ini dapat mengembangkan suatu organisasi dan kordinasi yang baik pada setiap jajaran anak cabang maupun ranting dari sebuah organisasi.

c. Dalam hal pemilihan wakil rakyat yang diselenggarakan dengan cara professional dan bukan dengan berdasarkan kedekatan atau hubungan saudara dan kebijkan ini masih sangat relevan dengan saat ini dimana dalam pemilihan pimpinan ataupun wakil rakta itu tidak berdasarkan Nepotisme atau pun hubungan dara dan system keekrabatan sehingga dalam pengambilan keputusan itu akan lebih bijaksana tanpa melihat nepotisme.

d. Aturan Woeker atau aturan mengenai pelaksanaan lintah darat dan saat ini masih berlaku dan berjalan dalam bentuk pembentukan Koperasi dimana ini berlaku sampai saat ini untuk mengurangi terjadinya system ijon yang akan menyengsarakan masyarakat.

e. Menolak milisi

f. Menolak Potongan Gaji

Kebijakan yang dilakukan oleh pemerintah belanda sangat merugikan rakyat atau masyarakat dan hal ini membuat hati Oto tergerak membuat kebijakan untuk menolak potongan gaji dan ini untuk mengurangi kemiskinan dan penderitaan rakyat dan ini sangat relevan dengan kondisi saat ini.

g. Memberikan kesempatan kepada kaum perempuan untuk ikut terjun dalam bidang politik dan kebijakan ini sangat relevan dengan kondisi saat ini dimana perempuan diberikan kesempatan untuk memasuki dunia politik dan emansipasi setiap wanita dapat menjadi pemimpin bahkan untuk memimpin Negara ini. 
3. Tipologi Kepemimpinan Oto dalam Perspektif Budaya Sunda

a. Guna, berarti pemimpin memberikan pengertian kegunaan perintah seorang pemimpin kepada bawahan agar terjadi kesamaan persepsi hal ini relatif sama dengan indikator kepemimpinan modern Satu visi.

b. Hookeun yang berarti kepercayaan diri orang yang diperintah dapat ditumbuhkan dengan cara menghargai prestasi kerjanya, hal ini sejalan dengan indikator percaya diri, dimana seorang pemimpin harus membangun rasa percaya diri kepada para bawahannya dengan cara memotivasi agar visi yang dibangun dapat tercapai.

c. Mukpruk mempunyai pengertian bahwa kepemimpinan perlu memberi kepercayaan kepada bawahan, sehingga mereka merasa dihargai kemampuannya.

d. Ngulas mempunyai pengertian bahwa kepemimpinan dituntut menumbuhkan kesadaran kepada bawahan agar tidak melaksanakan pekerjaan karena terpaksa dan dalam hal ini adalah kemampuan pemimpin menggungkapkan Visi dengan agar bawahan dalam melaksanakan pekerjaan tidak dengan terpaksa dan ini menimbulkan rasa memiliki yang kuat para bawahan terhadap institusi dimana mereka mengabdikan diri.

\section{DAFTAR PUSTAKA}

Creswell, John W. 2010. Research Desain Pendekatan Kuantitatif, Kualitatif dan Mixed. Yogjakarta. Pustaka Pelajar.

GaryYukl. 2001. Kepemimpinan dalam Organisasi. Terjemahan Budi Supriyanto. 2010. Jakarta: Indeks.

Iip D. Yahya. 2008. The Untold Stories.

Lubis, Nina H. 2003. Si Jalak Harupat : Biografi R. Oto Iskandar Dinata. Jakarta : PT Gramedia Pustaka utama

Sugiono. 2007. Metode Penelitian Pendidikan Pendekatan Kuantitatif, Kualitatif dan

R\& D. Bandung. Alfa Beta

Veithzal Rivai. 2004. Manajemen Sumber Daya Manusia Untuk Perusahaan. Cetakan Pertama. PT. Raja Grafindo. Jakarta. 